\title{
Lack of Association between Apolipoprotein E Polymorphism with Age at Onset of Subcortical Vascular Dementia
}

\author{
Hye Guk Ryu ${ }^{a}$ Sung-Won Youn ${ }^{b}$ Oh Dae Kwon ${ }^{c}$ \\ ${ }^{a}$ Department of Biological Science, College of Natural Sciences, Daegu University, \\ Departments of ${ }^{b}$ Radiology and ${ }^{\mathrm{c}}$ Neurology, School of Medicine, Catholic University of \\ Daegu, Daegu, South Korea
}

\section{Key Words}

Subcortical vascular dementia $\cdot$ Alzheimer's disease $\cdot$ Age at onset $\cdot$ Apolipoprotein E · Risk factors $\cdot$ White matter lesions

\begin{abstract}
Background and Purpose: The relationship between apolipoprotein $\mathrm{E}(\mathrm{Apo} E$ ) and onset of vascular dementia remains controversial. The aim of this study was to evaluate the relationship between ApoE polymorphism and the onset of subcortical vascular dementia (SVaD) compared to Alzheimer's disease (AD) and normal controls. Methods: The study was comprised of 61 patients with SVaD (42 Binswanger type, 19 lacunar type) and 112 patients with AD (16 early-onset $A D, 96$ late-onset AD) as well as 284 age-, gender- and education-matched normal controls. The diagnosis of SVaD was based on modified NINDS-AIREN criteria, and the diagnosis of AD was based on NINCDS-ADRDA criteria. ApoE polymorphism was genotyped in all participants. $\boldsymbol{R e}$ sults: None of the three ApoE alleles was more prevalent in SVaD patients compared to normal controls, which was the case when both Binswanger and lacunar types were analyzed separately. ApoE $\varepsilon 4$ did not accelerate the onset of SVaD (OR 1.66, 95\% Cl: 0.8-3.4), in contrast to a significant relation with late-onset AD (OR 3.78, 95\% Cl: 2.2-6.5). Conclusion: Our results suggest that ApoE polymorphism is not associated with the onset of SVaD and that the two subtypes of SVaD may share similar pathophysiologies.

Copyright $\odot 2012$ S. Karger AG, Basel
\end{abstract}




\section{Introduction}

Apolipoprotein E (ApoE) transports plasma protein in blood. ApoE $\varepsilon 4$ has been known to be a risk factor of familial [1] and sporadic Alzheimer's disease (AD) [2,3]. Along with AD, vascular dementia also has been studied to understand the relationship between ApoE $\varepsilon 4$ dose and the risk of earlier development of vascular dementia [4-10]. The results are not confirmatory and over half of the reports could not find ApoE $\varepsilon 4$ as a risk factor for vascular dementia $[6,7,10]$. Therefore, the relation between ApoE polymorphisms and vascular dementia remains a matter of study. The reason for this may be a lack of homogeneity in the diagnosis of vascular dementia due to varying diagnostic criteria and a lack of brain imaging in developing countries in which incidence of vascular dementia is higher than in developed countries [11]. Therefore, studies involving a homogeneous group of patients with vascular dementia who underwent brain imaging are needed. Subcortical vascular dementia (SVaD) is a subtype of vascular dementia, a relatively homogeneous group characterized by lacunar infarctions and white matter hyperintensities (WMHs) as well as focal signs and symptoms [12]. The pathogenesis has been thought to be based on small vessel pathology of the deep brain area [13]. It is divided into two subtypes, predominantly 'white matter cases', known as the Binswanger type, and predominantly 'lacunar cases' with multiple lacunae in the deep gray matter with white matter lesions [12].

The objective of this study was to explore the association of ApoE $\varepsilon 4$ with the age at onset of SVaD compared to AD and normal controls. We also tried to determine the differences between Binswanger and lacunar types in terms of ApoE polymorphism.

\section{Subjects and Methods}

\section{Subjects}

A total of 173 patients (127 females, mean age: $74.28 \pm 0.52$, ages: $52-88)$ were consecutively recruited from newly diagnosed $\mathrm{SVaD}$ and $\mathrm{AD}$ patients who had visited the Department of Neurology, Daegu Catholic University Medical Center, Daegu, South Korea, between April 2004 and March 2009. At the time of visit, mean disease duration for patients was $2.21 \pm 2.40$ years. Age-, gender-, and education-matched controls (a total of 284 controls, of whom 187 were females, mean age: $73.35 \pm 5.28$, ages: $58-88$ ) were selected from community-dwelling, non-demented older individuals after exclusion of cognitive impairment by neuropsychological tests and history of stroke by a neurologist. All participants were Korean and gave informed written consent before participating in this study. The Institutional Review Board of the Daegu Catholic University Medical Center approved the study protocol in 2007.

\section{Diagnosis}

Diagnosis of dementia was made according to DSM-IV criteria [14] and that of SVaD was based on modified NINDS-AIREN criteria [12]. Both Binswanger and lacunar types should be absent of cortical and/or cortico-subcortical, non-lacunar territorial infarcts and watershed infarcts, hemorrhages, signs of normal pressure hydrocephalus and specific causes of white matter lesions as multiple sclerosis, sarcoidosis or brain irradiation. Diagnosis of probable AD was made according to NINCDS-ADRDA criteria [15]. Exclusion criteria for $\mathrm{SVaD}, \mathrm{AD}$ and normal controls were: (1) history of significant hearing or visual impairment, (2) severe psychiatric illnesses, (3) diagnosis of both types of dementia, and (4) AD with modest or severe WMHs or previous stroke evidenced by MRI with cognitive symptoms before the onset of the first cerebrovascular event. 


\section{Evaluation of Brain MRI}

All dementia patients underwent brain MRI. The MRI (MR Excite, GE 1.5 tesla) scans included trans-axial T2- and T1-weighted, gradient-echo, fluid-attenuated inversion recovery (FLAIR) and coronal T1-weighted images. Lacunar infarcts were defined as small $(\geq 3$ $\mathrm{mm},<15 \mathrm{~mm}$ ) subcortical infarcts in the chronic stage, located in the basal ganglia, thalamus, internal capsule or corona radiata that appeared not to have occlusion of a single penetrating artery [16]. They had to show hypointensity on T1 imaging and gliotic rims on T2 imaging.

WMH was measured by axial FLAIR images. We rated the degree of WMH in two separated areas. Lesions in the periventricular area were measured as the longest vertical length from the ventricular wall and rated as P1 $(<5 \mathrm{~mm}), \mathrm{P} 2(\geq 5 \mathrm{~mm},<10 \mathrm{~mm})$ or P3 $(\geq 10 \mathrm{~mm})$. Lesions in the deep white matter were measured as the longest diameter and rated as D1 $(<10$ $\mathrm{mm})$, D2 ( $\geq 10 \mathrm{~mm},<25 \mathrm{~mm})$ and D3 $(\geq 25 \mathrm{~mm}$ ). The results were combined to rank the severity of WMH. Patients with D3P3 and one to five lacunar infarcts were included as a candidate for the diagnosis of Binswanger-type SVaD, and six or more lacunae were needed for the diagnosis of lacunar type [12]. MRIs with cortical ischemic lesions were excluded from the ratings. All MRI scans were rated by a neuroradiologist and a neurologist who did not have clinical information on the patients.

\section{Neuropsychological Tests}

The Seoul Neuropsychological Screening Battery (SNSB) [17], a standardized neuropsychological battery, was performed in $\mathrm{SVaD}$ and $\mathrm{AD}$ subjects. Among these tests, the components that could be scored were: digit span (forward and backward), the Korean version of the Boston Naming Test, written calculations, the Rey-Osterrieth Complex Figure Test, the Seoul Verbal Learning Test, the phonemic and semantic Controlled Oral Word Association Test (COWAT) and the Stroop Test. MMSE, Clinical Dementia Rating (CDR) and Geriatric depression scales were performed in controls. Clinical assessments include CDR [18], Barthel activities of daily living (B-ADL) [19], Geriatric depression scales [20], and modified Hachinski ischemia scales (HIS) [21].

\section{Age at Onset}

We interviewed the patients and all available informants, reviewed medical records to look for previous chronologies of cognitive and behavioral symptoms and asked the patient's caregiver to estimate the duration of symptoms commonly associated with $\mathrm{AD}$ [22] and $\mathrm{SVaD}$. The physician then estimated the age at onset to the nearest half year after resolving any discrepant information through further questioning and by relating hypothesized time frames to the patient's life events.

\section{ApoE Genotyping}

Genomic DNA was extracted from venous blood. Blood samples from the subjects were collected in EDTA-containing tubes, and the ApoE genotype was determined by polymerase chain reaction (PCR) [23].

\section{Statistical Analysis}

The comparisons of categorical variables for $\mathrm{SVaD}$ and $\mathrm{AD}$ with controls were analyzed by a $\chi^{2}$ test, and continuous variables were analyzed by ANOVA. A Fisher's exact test was computed when the expected frequency of any cell was less than 5. A Student's t test was used to analyze the average for continuous variables for parametric statistics, and the Mann-Whitney $U$ test was performed for nonparametric statistics. The age at onset of each subgroup associated with each ApoE allele was determined using linear regression analysis. OR and 95\% 
Table 1. General characteristics of controls and subjects with $\mathrm{SVaD}$ and $\mathrm{AD}$

\begin{tabular}{lcccc}
\hline & $\begin{array}{l}\text { SVaD } \\
(\mathrm{n}=61)\end{array}$ & $\begin{array}{l}\mathrm{AD} \\
(\mathrm{n}=112)\end{array}$ & $\begin{array}{l}\text { Controls } \\
(\mathrm{n}=284)\end{array}$ & p value \\
\hline Age & $75.05 \pm 5.46$ & $73.87 \pm 7.49$ & $73.35 \pm 5.28$ & $\mathrm{NS}$ \\
Male/female & $17 / 44$ & $29 / 83$ & $97 / 187$ & $\mathrm{NS}$ \\
Education & $3.92 \pm 4.41$ & $4.72 \pm 4.76$ & $3.66 \pm 3.38$ & $\mathrm{NS}$ \\
Age at onset & $72.90 \pm 6.18$ & $71.62 \pm 8.02$ & - & $\mathrm{NS}$ \\
K-MMSE & $19.31 \pm 4.37$ & $19.06 \pm 4.97$ & $24.37 \pm 3.82^{\mathrm{d}}$ & $<0.001$ \\
CDR & $1.07 \pm 0.33$ & $1.13 \pm 0.41$ & $0.15 \pm 0.24^{\mathrm{d}}$ & $<0.001$ \\
CDR/SOB & $5.05 \pm 2.46$ & $5.59 \pm 3.05$ & $0.18 \pm 0.39^{\mathrm{d}}$ & $<0.001$ \\
B-ADL & $18.57 \pm 2.53$ & $18.64 \pm 2.75$ & - & $\mathrm{NS}$ \\
GDS & $19.05 \pm 7.16$ & $17.75 \pm 6.99$ & $10.33 \pm 8.05^{\mathrm{e}}$ & $<0.001$ \\
HIS & $4.47 \pm 3.30$ & $3.15 \pm 2.65$ & - & $<0.05$ \\
\hline
\end{tabular}

Values are means $\pm \mathrm{SD}$. SVaD = Subcortical vascular dementia; $\mathrm{AD}=$ Alzheimer's disease; KMMSE $=$ Korean version of the Mini-Mental State Examination; CDR = Clinical Dementia Rating; CDR$\mathrm{SOB}=$ Clinical Dementia Rating/Sum of Box; B-ADL = Barthel-ADL; GDS = Geriatric depression scale; HIS $=$ Hachinski ischemia scales.

${ }^{a}$ Result of one-way ANOVA. ${ }^{b}$ Result of $\chi^{2}$ test. ${ }^{c}$ Result of Student's $t$ test. ${ }^{d}$ Significantly different from the other two groups ( $\mathrm{p}<0.001$ by post hoc Dunnett's method). ${ }^{\text {e }}$ Significantly different from the other two groups ( $\mathrm{p}<0.001$ by Scheffe's post hoc test).

CI were calculated between subjects with at least one ApoE $\varepsilon 4$ or at least one ApoE $\varepsilon 2$ and subjects with the ApoE $\varepsilon 3 / \varepsilon 3$ genotype using logistic regression analysis. All statistical analyses were performed using SPSS for Windows version 15.0 (SPSS Inc., Chicago, Ill., USA).

\section{Results}

\section{General Characteristics}

As shown in table $1, \mathrm{SVaD}$ and AD show significantly lower K-MMSE scores $(\mathrm{p}<0.001)$, CDR $(\mathrm{p}<0.001)$ and higher Geriatric depression scale scores $(\mathrm{p}<0.001)$ compared to the control subjects. No significant differences were found in scores for K-NPI, B-ADL, S-IADL and age at onset between the patients with $\mathrm{SVaD}$ or $\mathrm{AD}$, but HIS score was lower in AD patients $(\mathrm{p}<0.05)$.

\section{Frequency Distribution of ApoE Genotypes and Alleles}

Table 2 shows that the genotype distribution was not significantly different between $\mathrm{SVaD}$ and controls or between the Binswanger and lacunar types of SVaD. In contrast, the frequency of ApoE genotype distribution in the AD subjects was statistically different compared to controls $(\mathrm{p}=0.004)$. The ApoE $\varepsilon 3$ allele frequency was lower in the $\mathrm{AD}$ group compared to controls $(\mathrm{p}<0.001)$ and the SVaD group $(\mathrm{p}<0.05)$. The ApoE $\varepsilon 4$ frequency in the AD patients was higher than that of the controls $(\mathrm{p}<0.001)$ and $S V a D$ patients $(\mathrm{p}<0.05)$. In contrast, there was no significant difference between the SVaD group and the controls $(\mathrm{p}=0.314)$.

\section{Age at Onset of Each Subgroup of Dementia by ApoE Allele Status}

In a linear regression analysis with age at onset as the outcome and the four groups and the $\varepsilon 4$ allele as factors, the $\varepsilon 4$ allele was significantly associated with younger age at onset 
Table 2. Distribution of ApoE genotypes and alleles among controls and patients with $\mathrm{AD}$ and $\mathrm{SVaD}$

\begin{tabular}{|c|c|c|c|c|c|c|c|c|}
\hline & \multicolumn{3}{|l|}{ SVaD } & \multicolumn{3}{|l|}{$\mathrm{AD}$} & \multirow{2}{*}{$\begin{array}{l}\text { Controls } \\
(\mathrm{n}=284)\end{array}$} & \multirow{2}{*}{$\begin{array}{l}\mathrm{p} \\
\text { value }\end{array}$} \\
\hline & $\begin{array}{l}\text { Binswanger } \\
\text { type } \\
(\mathrm{n}=42)\end{array}$ & $\begin{array}{l}\text { Lacunar } \\
\text { type } \\
(\mathrm{n}=19)\end{array}$ & $\begin{array}{l}\text { total } \\
(\mathrm{n}=61)\end{array}$ & $\begin{array}{l}\text { EOAD } \\
(\mathrm{n}=16)\end{array}$ & $\begin{array}{l}\text { LOAD } \\
(\mathrm{n}=96)\end{array}$ & $\begin{array}{l}\text { total } \\
(\mathrm{n}=112)\end{array}$ & & \\
\hline \multicolumn{8}{|l|}{ Genotypes } & $\mathrm{NS}^{\mathrm{a}}$ \\
\hline$\varepsilon 2 / \varepsilon 2$ & $0(0)$ & $0(0)$ & $0(0)$ & $0(0)$ & $1(1.0)$ & $1(0.9)$ & $2(0.7)$ & $0.004^{\mathrm{b}}$ \\
\hline$\varepsilon 2 / \varepsilon 3$ & $2(4.8)$ & $4(21.1)$ & $6(9.8)$ & $1(6.3)$ & $5(5.2)$ & $6(5.4)$ & 31 (10.9) & $\mathrm{NS}^{\mathrm{c}}$ \\
\hline$\varepsilon 2 / \varepsilon 4$ & $0(0)$ & $0(0)$ & $0(0)$ & $0(0)$ & $3(3.1)$ & $3(2.7)$ & $3(1.1)$ & \\
\hline$\varepsilon 3 / \varepsilon 3$ & $30(71.4)$ & $12(63.2)$ & $42(68.9)$ & $11(68.8)$ & $51(53.1)$ & $62(55.4)$ & $209(73.6)$ & \\
\hline$\varepsilon 3 / \varepsilon 4$ & $10(23.8)$ & $2(10.5)$ & $12(19.7)$ & $3(18.8)$ & $31(32.3)$ & $34(30.4)$ & $39(13.7)$ & \\
\hline$\varepsilon 4 / \varepsilon 4$ & $0(0)$ & $1(5.3)$ & $1(1.6)$ & $1(6.3)$ & $5(5.2)$ & $6(5.4)$ & $0(0)$ & \\
\hline \multicolumn{9}{|l|}{ Alleles } \\
\hline$\varepsilon 2$ & $2(2.4)$ & $4(10.5)$ & $6(4.9)$ & $1(3.1)$ & $10(5.2)$ & $11(4.9)$ & $38(6.7)$ & \\
\hline$\varepsilon 3$ & $72(85.7)$ & 30 (78.9) & $102(83.6)^{\mathrm{e}}$ & $26(81.3)$ & $138(71.9)^{\mathrm{d}}$ & $164(73.2)^{\mathrm{d}}$ & 488 (85.9) & \\
\hline$\varepsilon 4$ & 10 (11.9) & $4(10.5)$ & $14(11.5)^{\mathrm{e}}$ & $5(15.6)$ & $44(22.9)^{\mathrm{d}}$ & $49(21.9)^{\mathrm{d}}$ & $42(7.4)$ & \\
\hline
\end{tabular}

$\mathrm{SVaD}=$ Subcortical vascular dementia; $\mathrm{AD}=$ Alzheimer's disease; $\mathrm{EOAD}=$ early-onset Alzheimer's disease; $\mathrm{LOAD}=$ late-onset Alzheimer's disease.

Results of the $\chi^{2}$ test: ${ }^{a} p$ value for SVaD versus controls. ${ }^{b} p$ value for AD versus controls. ${ }^{c} p$ value for SVaD versus AD. ${ }^{\mathrm{d}} \mathrm{p}<0.001$ compared to controls. ${ }^{\mathrm{e}} \mathrm{p}<0.05$ compared to AD.

$(\mathrm{t}=-2.052, \mathrm{p}<0.05)$ in only the late-onset $\mathrm{AD}$ group. The $\varepsilon 3$ allele and $\varepsilon 2$ allele were not associated with age at onset in any group (table 3 ).

\section{Odds Ratio for Each Dementia Group}

The cases of three groups were subdivided into two groups: those with at least one ApoE $\varepsilon 4$ and ApoE $\varepsilon 3 / \varepsilon 3$ individuals, and those with at least one ApoE $\varepsilon 2$ and ApoE $\varepsilon 3 / \varepsilon 3$ individuals. The OR for the patients carrying ApoE $\varepsilon 4 / \varepsilon 4$ or $\varepsilon 3 / \varepsilon 4$ in $\mathrm{AD}$ was 3.46 (95\% CI: 2.0-5.8, p < 0.001), and in late-onset AD it was 3.78 (95\% CI: $2.2-6.5, \mathrm{p}<0.001)$ compared to those who were carrying ApoE $\varepsilon 3 / \varepsilon 3$.

\section{Discussion}

$\mathrm{SVaD}$ is a known and common cause of vascular dementia [12], and more research is needed to differentiate it with $\mathrm{AD}$ and other dementia illnesses. The incidence of all three ApoE alleles in SVaD was not different from that of normal controls, in contrast to a significant difference between $\mathrm{AD}$ and normal controls with respect to $\varepsilon 4$ and $\varepsilon 3$ allele frequencies. There were also no differences between the Binswanger and lacunar types in allele frequencies and the genotypes of the ApoE polymorphism. On the contrary, the results showed an association between the presence of $\mathrm{ApoE} \varepsilon 4$ and younger age at onset of late-onset AD. Our results confirmed that there is no association between ApoE polymorphism with age at onset of SVaD.

The presence and gene dose of ApoE $\varepsilon 4$ was reported to be a risk factor for late-onset $\mathrm{AD}[1,2]$ in contrast to the controversies between $\mathrm{ApoE} \varepsilon 4$ and vascular dementia. The relation between ApoE and lipid metabolism [24, 25], which may affect cerebral atherosclerosis, indicated that there could be an association between ApoE and vascular dementia. There are 
Table 3. Age at onset of each subgroup of SVaD and AD by APOE allele status

\begin{tabular}{|c|c|c|c|c|c|c|c|c|}
\hline & SVaD & & & & $\mathrm{AD}$ & & & \\
\hline & $\begin{array}{l}\text { Binswange } \\
(\mathrm{n}=42)\end{array}$ & ype & $\begin{array}{l}\text { Lacunar ty } \\
(\mathrm{n}=19)\end{array}$ & & $\begin{array}{l}\text { EOAD } \\
(n=16)\end{array}$ & & $\begin{array}{l}\text { LOAD } \\
(\mathrm{n}=96)\end{array}$ & \\
\hline & $\mathrm{AAO}$ & $\mathrm{n}$ & $\mathrm{AAO}$ & $\mathrm{n}$ & $\mathrm{AAO}$ & $\mathrm{n}$ & $\mathrm{AAO}$ & $\mathrm{n}$ \\
\hline$\varepsilon 2$ allele & & & & & & & & \\
\hline$\varepsilon 2=2$ & & & & & & & 80.0 (NA) & 1 \\
\hline$\varepsilon 2=1$ & $72.5(10.6)$ & 2 & $69.5(5.7)$ & 4 & 64.0 (NA) & 1 & 73.4 (5.6) & 8 \\
\hline$\varepsilon 2=0$ & $74.3(6.0)$ & 40 & $70.1(5.4)$ & 15 & $56.4(5.7)$ & 15 & $74.1(5.2)$ & 87 \\
\hline$\varepsilon 3$ allele & & & & & & & & \\
\hline$\varepsilon 3=2$ & $73.7(5.0)$ & 30 & $71.0(5.4)$ & 12 & $55.9(5.8)$ & 11 & $74.88(5.1)$ & 51 \\
\hline$\varepsilon 3=1$ & 75.5 (8.5) & 12 & $67.8(5.4)$ & 6 & $60.2(5.6)$ & 4 & $73.1(5.3)$ & 39 \\
\hline$\varepsilon 3=0$ & & & 70.0 (NA) & 1 & 54.0 (NA) & 1 & $73.5(5.3)$ & 6 \\
\hline E4 allele & tus ${ }^{*}$ & & & & & & & \\
\hline$\varepsilon 4=2$ & & & 70.0 (NA) & 1 & 54.0 (NA) & 1 & $72.2(4.8)$ & 5 \\
\hline$\varepsilon 4=1$ & $76.1(8.5)$ & 10 & $64.5(3.5)$ & 2 & $59.0(6.1)$ & 3 & $72.8(5.1)$ & 34 \\
\hline$\varepsilon 4=0$ & $73.7(5.2)$ & 32 & $70.6(5.3)$ & 16 & $56.6(6.1)$ & 12 & $75.0(5.2)$ & 57 \\
\hline
\end{tabular}

Values are means $\pm \mathrm{SD} . \mathrm{SVAD}=$ Subcortical vascular dementia; $\mathrm{AD}=$ Alzheimer's disease; $\mathrm{AAO}=$ age at onset. $\mathrm{EOAD}=$ early-onset Alzheimer's disease; $\mathrm{LOAD}=$ late-onset Alzheimer's disease. $\mathrm{NA}=$ not available. ${ }^{*}$ Significant by linear regression analysis only in the LOAD group $(t=-2.052, p<0.05)$.

several explanations for the relation between ApoE polymorphism and vascular dementia. First, there could be interference of mixed-type dementia in detecting vascular dementia. To exclude mixed-type dementia, we strictly used temporal relationships between cerebrovascular events and onset of cognitive symptoms as an essential component for the diagnosis of SVaD. Additionally, we excluded AD with modest or severe WMHs or previous stroke evidence by the MRI of AD patients. Second, there may be ethnic differences between different populations. All patients and controls in this study were Korean and there may be differences with other ethnicities. As we previously reported, there were ethnic differences for the effect of ApoE polymorphism even on patients with AD [26]. Therefore, modification of the ApoE effect on vascular dementia might occur in some populations. In this study, there were no correlations between SVaD and ApoE polymorphism in terms of age at onset. Neither ApoE $\varepsilon 4$ nor ApoE $\varepsilon 2$ played a role regarding age at onset of $S V a D$. There were also no differences of ApoE allele frequencies between SVaD and the control groups. These results are consistent with a previous study $[6,7,10]$. Our study again separated SVaD into Binswanger and lacunar types to determine possible differences between the two subtypes of SVaD. However, both types did not show a significant relationship with ApoE polymorphism. A twin study [10] and studies of vascular pathophysiology [27, 28] strengthened the power of our negative findings. Contrary to the results of $\mathrm{SVaD}$, late-onset $\mathrm{AD}$ showed a significant correlation with onset age and ApoE $\varepsilon 4$, and overall $\mathrm{AD}$ subjects also showed a correlation between onset age and ApoE $\varepsilon 4$. Moreover, AD subjects showed significantly increased $\varepsilon 4$ and decreased $\varepsilon 3$ frequencies compared to those of normal controls which is also in agreement with a previous study [1-3].

The pathogenesis of SVaD has been thought to be related with small vessel diseases of the deep cerebral area [13], and it is divided into two subtypes, the lacunar type $[29,30]$ and the Binswanger type [16, 31], by clinical and radiological findings [12]. Pathologic findings 
of white matter lesions of SVaD include severe gliosis of the white matter and hyalination, intimal fibrosis and onion skinning of the long medullary arteries with multiple lacunae [16, 32]. Interference of the frontal subcortical circuit could be the reason for clinical symptoms of both types of SVaD. There are several reports presenting the clinical characteristics of Binswanger-type SVaD [29, 30, 33, 34]. However, to our knowledge, there is no report on the clinical and genetic characteristics of lacunar-type SVaD. Relative clinical inhomogeneity of the lacunar type and appearance of a new concept of strategic single-infarct dementia such as thalamic dementia could be the reason for absence in the study [35]. Even though there is some inhomogeneity in lacunar-type $\mathrm{SVaD}$, exploring exact clinical and genetic manifestations of lacunar-type SVaD as well as those of Binswanger-type SVaD has its own significance. We thought that the two subtypes of SVaD share genetic and pathophysiological mechanisms because of the shared small vessel pathologies. The criteria used in this study which obligates at least one lacuna for the diagnosis of Binswanger type could exclude other pathophysiologies such as hypoxic encephalopathy or some other lesions mimicking small artery disease. In this study, there were no differences between the two types of SVaD in terms of ApoE polymorphism, as expected. The lack of a genetic difference between the two types in terms of ApoE polymorphism again supports the fact that SVaD has common small vessel pathology. The reason why there was no correlation between ApoE polymorphism and SVaD could be explained as follows: to begin with, cerebral atherosclerosis and ischemia is a multifaceted disorder, and lipoproteins form only one of the many links intervening between inception of the lesion and development of the complicated plaque. Other explanations could be allelic frequency variation among ethnicities and differences in dietary practices, among others. Overall, the results of this study may indicate that small vessel pathology in deep cerebral areas of the brain is not affected by ApoE polymorphism in terms of age at onset and ApoE allele frequencies.

Both types of dementia in our study showed similar neuropsychological test scores in terms of K-MMSE, CDR and Geriatric depression scales. It has been thought that SVaD has a slow and progressive clinical course, and it is difficult to differentiate $\mathrm{SVaD}$ from $\mathrm{AD}$ by clinical course alone [12]. Therefore, it may be reasonable that Hachinski ischemia scores are only useful to differentiate multi-infarct dementia from AD. However, there was a significant difference in the Hachinski ischemia score between $\mathrm{AD}$ and $\mathrm{SVaD}$, which could be useful to differentiate one from the other. Though the clinical features of SVaD may not show apparent stepwise deterioration, the cognitive deterioration essentially shows a stepwise pattern, because of repetitive subcortical ischemic events, which result in minor neurological deficits [36]. A cohort study also showed that patients with MRI-defined SVaD often had more walking disorders than patients with cortical stroke [37].

This study has several limitations. First, the relatively small sample sizes for the subtypes of $\mathrm{SVaD}$ and early-onset $\mathrm{AD}$ reduced the power of the study to detect associations between ApoE polymorphism and age at onset. In addition, the variable prevalence of some of the rare alleles within the subgroups, such as the absence of the $\varepsilon 2$ homozygotes in the three smaller groups or the absence of $\varepsilon 4$ homozygotes among Binswanger-type SVaD, limits the conclusions. On the other hand, these findings may reflect true variation among the subgroups not just reflecting random variation. Second, this study uses clinic-based patients and our findings may not correlate with that of a population-based study. However, the allelic frequencies of the $\mathrm{AD}$ patients in our sample are consistent with a previous Korean study [7]. Despite these limitations, this is the first study to investigate the relationship of the two types of SVaD with ApoE polymorphism.

In summary, this study showed that ApoE polymorphism was not related with the onset of $\mathrm{SVaD}$, and it may contribute to the understanding of the pathophysiology of SVaD. 


\section{Acknowledgement}

This work was supported by a grant from the Research Institute of Medical Science of the Catholic University of Daegu, South Korea (2007).

\section{References}

1 Olarte L, Schupf N, Lee J, Tang M, Santana V, Williamson J, Maramreddy P, Tycko B, Mayeux R: Apolipoprotein E epsilon4 and age at onset of sporadic and familial Alzheimer disease in Caribbean Hispanics. Arch Neurol 2006;63:1586-1590.

-2 Corder E, Saunders A, Strittmatter W, Schmechel D, Gaskell P, Small G, Roses A, Haines J, PericakVance M: Gene dose of apolipoprotein E type 4 allele and the risk of Alzheimer's disease in late onset families. Science 1993;261:921-923.

-3 Okuizumi K, Onodera O, Tanaka H, Kobayashi H, Tsuji S, Takahashi H, Oyanagi K, Seki K, Tanaka M, Naruse S: ApoE-epsilon 4 and early-onset Alzheimer's. Nat Genet 1994;7:10-11.

-4 Chuang YF, Hayden KM, Norton MC, Tschanz J, Breitner JC, Welsh-Bohmer KA, Zandi PP: Association between APOE epsilon4 allele and vascular dementia: The Cache County study. Dement Geriatr Cogn Disord 2010;29:248-253.

5 Luthra K, Tripathi M, Grover R, Dwivedi M, Kumar A, Dey AB: Apolipoprotein E gene polymorphism in Indian patients with Alzheimer's disease and vascular dementia. Dement Geriatr Cogn Disord 2004;17:132-135.

-6 Nakayama S, Kuzuhara S: Apolipoprotein E phenotypes in healthy normal controls and demented subjects with Alzheimer's disease and vascular dementia in Mie Prefecture of Japan. Psychiatry Clin Neurosci 1999;53:643-648.

-7 Kim KW, Youn JC, Han MK, Paik NJ, Lee TJ, Park JH, Lee SB, Choo IH, Lee DY, Jhoo JH, Woo JI: Lack of association between apolipoprotein E polymorphism and vascular dementia in Koreans. J Geriatr Psychiatry Neurol 2008;21:12-17.

8 Slooter A, Cruts M, Kalmijn S, Hofman A, Breteler M, Van Broeckhoven C, van Duijn C: Risk estimates of dementia by apolipoprotein $\mathrm{E}$ genotypes from a population-based incidence study: the Rotterdam Study. Arch Neurol 1998;55:964-968.

-9 Yang J, Feng G, Zhang J, Hui Z, Breen G, St Clair D, He L: Is ApoE gene a risk factor for vascular dementia in Han Chinese? Int J Mol Med 2001;7:217-219.

-10 Bergem AL, Engedal K, Kringlen E: The role of heredity in late-onset Alzheimer disease and vascular dementia. A twin study. Arch Gen Psychiatry 1997;54:264-270.

$\checkmark 11$ Brayne C: The elephant in the room - healthy brains in later life, epidemiology and public health. Nat Rev Neurosci 2007;8:233-239.

-12 Erkinjuntti T, Inzitari D, Pantoni L, Wallin A, Scheltens P, Rockwood K, Roman GC, Chui H, Desmond DW: Research criteria for subcortical vascular dementia in clinical trials. J Neural Transm Suppl 2000;59:23-30.

-13 Roman GC, Tatemichi TK, Erkinjuntti T, Cummings JL, Masdeu JC, Garcia JH, Amaducci L, Orgogozo JM, Brun A, Hofman A: Vascular dementia: diagnostic criteria for research studies. Report of the NINDS-AIREN International Workshop. Neurology 1993;43:250-260.

14 American Psychiatric Association: Diagnostic and statistical manual of mental disorders: DSM-IV. Washington, D.C.: American Psychiatric Association; 1994.

-15 McKhann G, Drachman D, Folstein M, Katzman R, Price D, Stadlan EM: Clinical diagnosis of Alzheimer's disease: report of the NINCDS-ADRDA Work Group under the auspices of Department of Health and Human Services Task Force on Alzheimer's Disease. Neurology 1984;34:939-944.

-16 Fisher CM: Lacunes: small, deep cerebral infarcts. 1965. Neurology 1998;50:841 and 11 pages following.

17 Kang Y, Na D: Seoul Neuropsychological Screening Battery; in Kang Y, Na DL (eds): Seoul Neuropsychological Screening Battery. Incheon: Human Brain Research and Consulting Co.; 2003.

$\checkmark 18$ Morris JC: The Clinical Dementia Rating (CDR): current version and scoring rules. Neurology 1993; 43:2412-2414. 
19 Mahoney FI, Barthel DW: Functional Evaluation: the Barthel Index. Md State Med J 1965;14:61-65.

-20 Yesavage JA, Brink TL, Rose TL, Lum O, Huang V, Adey M, Leirer VO: Development and validation of a geriatric depression screening scale: a preliminary report. J Psychiatr Res 1982;17:37-49.

-21 Rosen WG, Terry RD, Fuld PA, Katzman R, Peck A: Pathological verification of ischemic score in differentiation of dementias. Ann Neurol 1980;7:486-488.

-22 Doody RS, Dunn JK, Huang E, Azher S, Kataki M: A method for estimating duration of illness in Alzheimer's disease. Dement Geriatr Cogn Disord 2004;17:1-4.

-23 Ryu HG, Kwon OD: Apolipoprotein E epsilon 4 allele is not associated with age at onset or MMSE of Parkinson's disease in a Korean study. Parkinsonism Relat Disord 2010;16:615-617.

-24 Brewer HB Jr, Zech LA, Gregg RE, Schwartz D, Schaefer EJ: NIH conference. Type III hyperlipoproteinemia: diagnosis, molecular defects, pathology, and treatment. Ann Intern Med 1983;98:623-640.

-25 Gregg RE, Zech LA, Schaefer EJ, Stark D, Wilson D, Brewer HB Jr: Abnormal in vivo metabolism of apolipoprotein E4 in humans. J Clin Invest 1986;78:815-821.

-26 Kwon OD, Khaleeq A, Chan W, Pavlik VN, Doody RS: Apolipoprotein E polymorphism and age at onset of Alzheimer's disease in a quadriethnic sample. Dement Geriatr Cogn Disord 2010;30:486491.

-27 Nielsen AS, Ravid R, Kamphorst W, Jorgensen OS: Apolipoprotein E epsilon 4 in an autopsy series of various dementing disorders. J Alzheimers Dis 2003;5:119-125.

-28 Betard C, Robitaille Y, Gee M, Tiberghien D, Larrivee D, Roy P, Mortimer JA, Gauvreau D: Apo E allele frequencies in Alzheimer's disease, Lewy body dementia, Alzheimer's disease with cerebrovascular disease and vascular dementia. Neuroreport 1994;5:1893-1896.

-29 Poirier J, Derouesne C: The concept of cerebral lacunae from 1838 to the present. Rev Neurol (Paris) 1985; 141:3-17.

-30 Besson G, Hommel M: Historical aspects of lacunes and the 'lacunar controversy'. Adv Neurol 1993; 62:1-10.

-31 Blass JP, Hoyer S, Nitsch R: A translation of Otto Binswanger's article, 'The delineation of the generalized progressive paralyses'. 1894. Arch Neurol 1991;48:961-972.

32 Alzheimer A: Die Seelenstorungen auf arteriscleroticsher Grundlage. Allgem Z Psychiatr Psych Gerichtl Med 1902;59:695-711.

-33 Higuchi S, Arai H, Nakagawa T, Muramatsu T, Sasaki H, Trojanowski JQ: The apolipoprotein E gene in Binswanger's disease and vascular dementia. Clin Genet 1996;50:459-461.

-34 Kwon JC, Kim EG, Kim JW, Kwon OD, Yoo BG, Yi HA, Choi NC, Ahn SY, Lee BH, Kang MJ, Choi DS; BKVD Study Group: A multicenter, open-label, 24-week follow-up study for efficacy on cognitive function of donepezil in Binswanger-type subcortical vascular dementia. Am J Alzheimers Dis Other Demen 2009;24:293-301.

-35 Bogousslavsky J, Regli F, Uske A: Thalamic infarcts: clinical syndromes, etiology, and prognosis. Neurology 1988;38:837-848.

- 36 Loeb C, Gandolfo C, Croce R, Conti M: Dementia associated with lacunar infarction. Stroke 1992; 23:1225-1229.

-37 Pohjasvaara T, Mantyla R, Ylikoski R, Kaste M, Erkinjuntti T: Clinical features of MRI-defined subcortical vascular disease. Alzheimer Dis Assoc Disord 2003;17:236-242. 